\title{
Assessing Multisectoral Coordination for Nutrition Policy Effectiveness: Analysis of Facilitators, Constraints and Solutions for Implementation in Ethiopia
}

\section{Eileen Kennedy ( $\nabla$ eileen.kennedy@tufts.edu )}

Tufts University Friedman School of Nutrition Science and Policy https://orcid.org/0000-0003-05099284

\section{Meghan Kershaw}

Tufts University Friedman School of Nutrition Science and Policy

Sibhatu Biadgilign

Consultant

\section{Rahel Gizaw}

Tufts University Friedman School of Nutrition Science and Policy Jennifer Stickland

Tufts University Friedman School of Nutrition Science and Policy

\section{Research}

Keywords: Nutrition, governance, policy, multisector, global health, food security

Posted Date: December 10th, 2020

DOl: https://doi.org/10.21203/rs.3.rs-123629/v1

License: (c) (i) This work is licensed under a Creative Commons Attribution 4.0 International License.

Read Full License 


\section{Abstract}

\section{Background}

Effective implementation is an essential element for achieving success in multisector nutrition plans. The present study is follow-up to research conducted in 2013 - 2014. The current research utilizes the same protocol and targets the same regions of Ethiopia that were included in the initial study. The aim of the present research is to ascertain the factors that have enabled and sustained effective multisectoral coordination to inform ongoing support for multisector coordination through current activities.

\section{Methods}

The study was qualitative with purposing sampling of twelve woredas, each of which represented one of three groups receiving different levels of interventions under the initial study. Data was collected through Key Informant Interviews of the heads of the woreda-level sector offices using a standardized and semistructured questionnaire. Focus Group Discussions were also held with nutrition focal/technical personnel working in different sectors, purposefully selected from relevant woreda sectors. Coding and analysis were done using Atlas.ti 8.1.3.

\section{Results}

Results indicate that progress has been made on key elements such as awareness of multisector nutrition plans and organization and functionality of the technical committees, however, competing priorities and lack of leadership and understanding of roles and responsibilities have hindered the effectiveness of regional coordination structures and implementation of the Government of Ethiopia's National Nutrition Program.

\section{Conclusions}

In order to address the gaps and constraints to effective implementation of the National Nutrition Program identified in the present study, different strategies need to be employed to create better awareness, ownership, understanding, and motivation for policy/decision making officials, technical experts, coordinating bodies, and supporting organizations. This paper provides recommendations to address these and future challenges for effective implementation of multisectoral coordination for nutrition policy effectiveness in the post-2020 period.

\section{Background}

The Government of Ethiopia (GoE) has demonstrated a strong policy commitment to nutrition through development of a National Nutrition Strategy (NNS) in 2008 [1], followed by a National Nutrition Program I (NNP I) (2008-2015) [2]. The follow-on National Nutrition Program II (NNP II) (2016-2020) [3], which builds on the earlier plan and has a specific focus on the 1,000 days from pregnancy to age two, was launched by the Government of Ethiopia in December 2016 and includes the Seqota Declaration [4], a 
high-level commitment to ending child undernutrition by 2030. There is increased awareness in Ethiopia that at both the global and national levels, investment in nutrition is key to development of human capital. Indeed, Ethiopia has made progress in decreasing malnutrition. Between 2000 and 2019, based on Demographic and Health Surveys (DHS) data $[5,6]$, stunting decreased from $58-37 \%$ and during the same time period, underweight was reduced from $41-21 \%$. Wasting has remained relatively the same at about $10 \%[5,6]$. While progress has been made in improving nutrition, the $\mathrm{GoE}$, with its developmental partners, wants to accelerate the rate of decrease in levels of malnutrition, especially stunting. Both of the NNPs have emphasized strengthening the implementation of nutrition-sensitive and specific interventions across sectors and establishing and strengthening the national and sub national multisector coordination bodies as critical in achieving the goals, recognizing the importance of addressing multisectoral issues with multisectoral solutions. There are 13 sectoral ministries that are signatories of the NNP II [3], signifying the importance and scope of multisectoral coordination required in order to successfully implement this program.

The Feed the Future Ethiopia Growth through Nutrition Activity is a five-year, multisectoral nutrition project, which aims to improve the nutritional status of women and young children in Ethiopia's four productive regions (Amhara, Oromia, SNNP and Tigray), focusing on the critical first 1,000 days of a child's life - from conception through age two. The project is funded by the U.S. Agency for International Development (USAID) and implemented by Save the Children International, with a consortium of local and international partners. Growth through Nutrition builds upon the accomplishments of USAID's prior Empowering New Generations to Improve Nutrition and Economic Opportunities (ENGINE) program. The project works across all levels of government and society to support country-led policies to bring intensified multisectoral nutrition programming to communities and households, through gender equality and women's empowerment in sustainable approaches and integration of nutrition sensitive activities.

Key components of both the previous ENGINE project and the current Growth through Nutrition Activity are support for the NNP I \& II [2,3] and strengthening of the implementation of multisectoral coordination at the national, regional, and district/woreda levels. Under ENGINE, the project provided support to the NNP, as well as the revision in 2013 and the development of the NNP II. ENGINE also supported the creation and capacity building activities of national, regional, and woreda level multisectoral coordination bodies and nutrition technical committees. A study conducted in 2013/14 examined the facilitators and constraints of implementing a multisector nutrition program [7). Results indicate that awareness of the multisectoral plans at the subnational level was extremely limited. This was problematic, since much of the NNP implementation occurs at the woreda and kebele levels. During year four of the project (20142015), ENGINE identified ten woredas to serve as models of multisectoral nutrition coordination and helped to establish coordinating mechanisms. ENGINE also provided technical and financial support to woreda multisectoral coordination meetings in Amhara, Oromia, SNNP and Tigray regions to orient woreda implementing sectors to the NNP and ensure nutrition is included in each sector's woreda plan.

Many of these activities have been continued under the Growth through Nutrition Activity. In the first two years of the project, activities included supporting the establishment and/or strengthening of nutrition 
coordination committees in all intervention woredas (70 woredas) as recommended in NNP II [3]. Prior to establishing the coordination bodies, the project provided financial and technical support to multisector coordination meetings held in some of the regions, i.e. Tigray and SNNP. The project also supported functionality of multisectoral bodies, measured by holding regular meetings, conducting supportive supervision at the local level, and budgeting for nutrition. Growth through Nutrition has provided intensive support to ten selected Model woredas so that they can serve as centers of excellence to showcase and ensure functional, multisectoral coordination mechanisms and better sectoral performance for NNP implementation in the four regions.

This new research conducted during the first year of the Growth through Nutrition Activity was designed to follow up on the support provided under ENGINE, especially to Model woredas to support the establishment and ongoing implementation of the woreda multisectoral coordination bodies and nutrition technical committees, and to ascertain the factors that have enabled and sustained effective multisectoral coordination.

The overall objective of the present research is to assess the impact of ENGINE on multisector coordination during the period from 2014 to 2018 to inform ongoing support for multisector coordination through the Growth through Nutrition Activity.

This Growth through Nutrition research builds on previous research on NNP implementation at the national and woreda levels conducted under ENGINE. The process research that was conducted in 2013/14 [7] found that (1) collaboration/coordination, (2) lack of awareness of the multisector nutrition plan, (3) communications, and (4) budget were the main constraints to effective implementation at the woreda level. The 2013/14 study [7] was conducted when the NNP was in the early stages of implementation and ENGINE had only begun providing support at the national and regional levels. Following the end of ENGINE and NNP I in 2015, there was a gap until the release of NNP II at the end of 2016. Growth through Nutrition began some of its multisectoral support activities in 2017. This research visited the key woreda leadership in 2017 to understand the outcome of the woreda level support and transition period.

\section{Methods}

This study was conducted in September 2017 in four regions - SNNP, Oromia, Amhara and Tigray. The study was qualitative with purposing sampling of twelve woredas, three from each of the four regions. The woredas in each region represented one of three groups receiving different levels of interventions under the ENGINE program, identified as Model woredas (MW), non-Model woredas (NMW), and nonENGINE woredas (NEW).

In year four of the ENGINE project, 10 woredas were identified to serve as models of multisectoral nutrition coordination and provide evidence and documentation for effective multisector coordination, called "Model woredas." Selection of these 10 woredas was based on: (1) receiving the complete package of ENGINE interventions including livelihood, water, hygiene, and sanitation (WASH), and Social and 
Behavior Change Communication (SBCC), (2) accessibility, and (3) commitment of woreda leaders to implementation of the NNP. In these woredas, ENGINE supported the establishment of multisectoral coordination bodies mainly through frequent technical and financial support to conduct coordination meetings. In addition, these Model woredas received frequent supportive supervision - usually monthly and integrated supportive supervision by including other sectors. These woredas received support from mid-2014 until the end of ENGINE in 2016. Four of these woredas (one from each of the four regions) were chosen for the study.

In other woredas that did not meet all the criteria for Model woredas, ENGINE still provided support for the establishment of multisectoral coordination bodies, but they did not receive the frequent and intensive supportive supervision and follow-up that the Model woredas received. These woredas are referred to as "Non-Model woredas" (NMWs). Four of these woredas (one from each of the four regions) were chosen for the study.

These (Model and non-Model) woredas represented the intervention woredas in the study. In addition, four non-ENGINE woredas which received no ENGINE support at all were included in the study as nonintervention woredas. These woredas were selected to be non-adjacent to the intervention woredas to avoid contamination. Four of these woredas (one from each of the four regions) were chosen for a total of twelve study woredas.

The data collection was done through Key Informant Interviews (KIIs) at the woreda and regional levels using a standardized and semi-structured questionnaire in the local language. There were six interviews in each woreda representing a purposive sample of the heads of the woreda-level NNP implementing sector offices. The sectors included district administration, health, agriculture, water and energy, education, finance, and economic development and represented the expected members of the woreda nutrition coordination body. Additionally, one KII with a regional-level NGO representative and one KII with a regional nutrition focal person from the Regional Health Bureau were conducted, for a total of $80 \mathrm{KIls}$ (72 woreda-level KII and eight regional).

Focus group discussions (FGDs) were also conducted at the woreda level in the local language. The participants for the FGDs were nutrition focal/technical personnel working in different sectors, purposefully selected from relevant woreda sectors. One FGD was held per woreda with 8-10 participants, including nutrition focal persons or technical persons from the woreda NNP implementing sectors, for a total of 12 FGDs. The focus group discussants were representative of the intended members for the woreda nutrition technical committee.

Informed consent was obtained from FGD participants and individual key informants. The Tufts University Institutional Review Boards (IRB) approved the study protocol as well as the Ethiopian Public Health Institute (EPHI).

The audio recordings of the KIls and FGDs were transcribed and translated to English for analysis. For the purpose of analysis, respondents were grouped into three woreda groups: ENGINE Model, ENGINE non- 
Model, and non-ENGINE woredas. Coding and analysis were done using Atlas.ti 8.1.3.

The study protocol and tools were developed by the Growth through Nutrition team from Tufts University. A consulting firm was hired to manage the hiring and training of data collectors as well as carry out the data collection process in the field. The consulting firm was also responsible for transcribing the audio recordings into English and conducting the preliminary coding of the transcripts. Although the initial coding was conducted by the consulting firm, extensive additional cleaning and coding was required from the Tufts team to ensure the quality of the final analysis and reporting. Data analysis was conducted by the Tufts University researchers.

\section{Results}

\section{Regional Level Interviews}

The regional level interviews were not meant to be a representative sample of this level of stakeholder. They do, however, provide some insights into the experiences and concerns of important stakeholder groups. The interviews at the regional level were grouped by representatives from regional NonGovernmental Organization (NGO) partners and a nutrition focal person or expert from each of the four regional health bureaus. Both groups were asked similar questions about their knowledge and experience with the implementation of the NNP, Regional Nutrition Coordinating Bodies (RNCBs), and Regional Nutrition Technical Committees (RNTCs), and the successes and challenges to multisectoral coordination. ENGINE helped support the establishment of Regional Coordination Bodies and Regional Technical Committees in Oromia, Amhara, Tigray, SNNP and Somali regions. Unfortunately, despite all the assistance from the project and partners, the Regional Coordination Bodies did not achieve the same success as the national level, and by year five, only the technical committees remained functional.

There were some common themes which emerged from the individual, regional level interviews. The most consistent comments were related to lack of awareness about the importance of nutrition, in particular, awareness from what were described as high-level officials. This lack of awareness was linked to a second concern about lack of commitment, in particular, from sector leaders. Almost all interviews from each region indicated that health and agriculture are the only responsive sectors in the multisector implementation while other sectors including women's affairs, trade and industry, etc. are lagging behind the others. In one respondent's words, "The proactive sectors are health and agriculture. The reason being lack of commitment from the other sectors." Well noted in many responses was that weak commitment hindered functionality of the coordination structures and implementation of the NNP. Responses from KIls with nutrition focal personnel in the four regions show that although Regional Nutrition Coordinating Bodies and Regional Nutrition Technical Committees were established in each, there were reservations about the functionality of the technical committee and coordination body in terms of not meeting regularly and limited involvement from all sectors. In one of the regions, the RNTC is mentioned as stronger and more functional than the RNCB. According to one respondent, in his/her region, "we have 
nutrition technical committee which is relatively strong as compared to coordination body which is not yet functional at regional level."

Staff turnover (sector leaders, nutrition focal persons) was most frequently mentioned as a challenge in the implementation of the NNP, affecting the functionality of coordination bodies and technical committees, followed by budget needs. One specific quote captures this sentiment, "The main problem here is the trained and signed agreement officials changed their offices, even changed to another place, therefore due to such movement, these committees are not functional for some period of time."

The interviews from NGO representatives also reflected the need to strengthen the RNCBs and RNTCs in order to improve the implementation of NNP program. Similar to the responses from regional nutrition focal persons, almost all indicated the importance of sector leaders from agriculture and health sectors to give more attention to nutrition. One NGO representative also suggested the RNCB be chaired by a regional president to lend more weight and increase the commitment of sectors to NNP implementation.

A challenge that was highlighted was the need for better integration of sectors in order to successfully achieve the objectives of the NNP. Almost all of the regional respondents reported that integration across regional, zonal and woreda levels was critical to the goals of the NNP, reflected by the quote, "I don't think good work has been done on integration (Regional KII)."

Regional interviewees had some pragmatic suggestions as to how integration and overall delivery of services could be achieved. First and foremost was the need for a strong, active, regional coordination committee. While people indicated that a committee structure may exist, it often is not active. Indeed, there was consensus that the coordination structures needed to be strengthened at all levels - regional, zonal and woreda levels. Other programmatic suggestions include providing frequent capacity building training and increasing sector leaders' commitment and accountability to increasing collaboration/integration among the different sectors.

Finally, there was explicit acknowledgement that government cannot accomplish the goals of the NNP alone. Implementing partners are critical to success. The spirit of this comment was reinforced by the observation that in areas where there are active partnerships, progress in implementation of the NNP is more apparent.

\section{Woreda Level Findings}

\section{Woreda Multisectoral Nutrition Coordination Bodies}

The research team compared interviews from the sector heads from the study woredas, including the woreda administrator, and compared results to the focus group responses and desk review conducted of documents about the multisectoral coordination body, to establish a more complete picture of its existence and functionality. The results are summarized in the table below (Table 1). 
Table 1

Reported Existence and Functionality of Woreda Multisectoral Coordination Bodies by Project Group

\begin{tabular}{|llll|}
\hline & $\begin{array}{l}\text { Model } \\
\text { Woredas }\end{array}$ & $\begin{array}{l}\text { Non-Model } \\
\text { Woredas }\end{array}$ & $\begin{array}{l}\text { Non-ENGINE } \\
\text { Woredas }\end{array}$ \\
\hline $\begin{array}{l}\text { Number of Woredas reported functional Woreda } \\
\text { Multisectoral Coordination Body }\end{array}$ & 2 & 1 & 0 \\
\hline $\begin{array}{l}\text { \% Functional number confirmed with documentation } \\
\text { (MOU/Minutes, etc.) }\end{array}$ & $100 \%$ & $100 \%$ & N/A \\
\hline Number created but not functional/meeting regularly & 2 & 2 & 1 \\
\hline Number newly created (Growth through Nutrition) & 0 & 0 & 1 \\
\hline No committee reported & 0 & 1 & 2 \\
\hline$\%$ Chaired by Woreda Admin & $100 \%$ & $66 \%$ & $100 \%$ \\
\hline
\end{tabular}

To evaluate the existence and functionality of the multisectoral coordination bodies and information given by the focus group discussants, Klls with woreda sector leads were used to gauge the awareness of and familiarity with these institutions. The respondents were asked about the existence of these bodies, who was the Chair, when they were established, how often they meet, if they consider them functional, and who provided them with support. In addition, a desk review of documents related to the multisectoral coordination and technical committee was carried out, which included on-hand availability and inspection of terms of reference (TORs), meetings minutes, and agendas.

Although it was reported that coordinating bodies were established in all of the Model and non-Model Woredas, only two of the Model woredas still appeared to have functioning coordination bodies; the other two were not considered functional by respondents and no documentation could be found to confirm functionality. Non-Model woredas had only one functional woreda coordinating body. All of the coordinating bodies, functional and non-functional, were reported to be chaired by the woreda administrators, except in one non-Model woreda where the Administration Head reported recently delegating the Health Office to a lead due to work burden (non-functional).

In the Model woreda focus group discussions, the discussants confirmed that two woredas had functioning multisectoral coordination bodies led by the woreda administrator. In one of the woredas, only one of the respondents had heard of such a committee but did not think it had ever truly been functional. In the fourth Model woreda, none of the respondents were aware of the creation of a nutrition multisectoral coordination body, although they saw great need for one and strongly recommended that it be established. These findings were confirmed in interviews with administrators of the Model woredas. One woreda administrator was not available for interview but the information was confirmed by the health office head. In another woreda, the findings from the woreda administrator and the focus group discussions were the opposite, and the respondent was not aware of the coordinating body. In this case, the woreda administrator had been in the job for less than one year. In both of the woredas where the coordinating bodies were no longer functional, the woreda administrator had arrived after the creation of 
the committee. Reasons given for lack of functionality were lack of budget to carry out joint activities and lack of support, as one respondent explained, "But, now we do not have involvement in NNP because after ENGINE was phased out, the committee is not active" (KII Woreda Administrator, Model Woreda). For the functional woredas, other sector heads from the Model woredas who were interviewed still expressed concern about the functionality of the coordination bodies, expressing that there wasn't consistent leadership, and that it is difficult for all sectors to participate equally due to work loads.

In two of the non-Model woredas, the focus group discussants confirmed that multisectoral coordination bodies were established and functioned initially, but were no longer functional after 2016 when the project phased out. One woreda group also mentioned that the United Nations Children's Fund (UNICEF) provided support to the body which also phased out around the same time. In the other two non-Model woredas, the focus group discussants were much less familiar with the idea of a multisectoral coordinating body, but at least one respondent from each group confirmed that a group was initiated in each woreda but was never functional.

Almost all focus groups talked about the need for attention and commitment from the woreda sector heads as crucial to facilitating greater multisectoral coordination. In interviews with the woreda administration heads in the non-Model woredas, two of the respondents were not familiar with the NNP or with the establishment of a multisectoral coordination body. One reported that there was a committee, but that they had delegated leadership to the health office due to the burden of activities during the last year (reported non-functional). Finally, the fourth administrator reported active engagement and ownership of the multisectoral committee in his/her woreda, reporting "Yes, there is formal established committee with its responsible sectors. The chair person is woreda administrator. There is a schedule set and has the objective of leading, evaluating the program, provision of feedback, and giving direction. We are now practicing accordingly" (Woreda Administrator, non-Model). This chair had been in the position longer than the other three non-Model and Model and non-ENGINE administrators.

In the non-ENGINE woredas, the focus group discussants mostly confirmed the results from the KI individual interviews regarding the multisectoral coordination bodies as only formed but non-functional in one woreda. In one woreda, the FGD said that there was an active committee but this was explained by the woreda administrator to be a committee for food security and drought, not to coordinate nutrition. Out of the four woreda administrators that were interviewed from the non-ENGINE woredas, all confirmed that there were no currently active multisectoral bodies. In one woreda, the chair reported that they were recently working with Save the Children International to establish one. Another said that they had plans to establish one in the future. The remaining two were not aware of any committees or of the NNP.

\section{Woreda Nutrition Technical Committees}

Focus group discussions were conducted in each woreda of the four regions included in this study for a total of 12 focus groups. The focus group discussions were held with approximately 10 woreda focal persons from the sectors in each woreda that would normally be included in the woreda-level nutrition technical committee, i.e. health, education, agriculture, livestock, finance, women's and youth affairs, 
water and irrigation, food security, and social affairs. The respondents were asked to comment on their awareness of nutrition problems and the plans and projects working to alleviate the issues, with a focus on the NNP as well the challenges and constraints to multisectoral collaboration in the woreda.

In the Model woredas, findings from the FGDs were more mixed than expected (Table 2). In two of the four model woredas, the FGD discussants had a strong understanding of their sector's role in the NNP and reported that there was a functional multisectoral coordinating body and Nutrition Technical Committee. Both active woreda nutrition technical committees (WNTCs) were led by the health sector. Despite the presence of the technical committees, there were several challenges shared about the ability of the committees to operate effectively. One major issue raised was the high turnover of sectoral focal persons. Another problem identified was the challenge of finding a time when everyone could meet, as different sectors are busy at different times, therefore, not all sectors participate equally in what seems to be an "on demand" basis. A third challenge raised by several participants was how nutrition activities may be seen as supplemental to the sector plan and that sector leads may not allocate time to focal persons to dedicate to committee work. As one participant explained, "It will be good if sector heads are aware of nutrition activities and allow focal persons to work freely on nutrition." Another added, "The main challenge is sector heads are very busy with competing priorities most of the time. So, if heads give the responsibility to technical teams, the collaboration will be effective."

Table 2

Reported Existence and Functionality of Woreda Nutrition Technical Committees by Project Group

\begin{tabular}{|llll|}
\hline & $\begin{array}{l}\text { Model } \\
\text { Woredas }\end{array}$ & $\begin{array}{l}\text { Non-Model } \\
\text { Woredas }\end{array}$ & $\begin{array}{l}\text { Non-ENGINE } \\
\text { Woredas }\end{array}$ \\
\hline $\begin{array}{l}\text { Number of Woredas with functional Woreda } \\
\text { Nutrition Technical Committee }\end{array}$ & 1 & 0 & 1 \\
\hline Number created but not functional/meeting regularly & 1 & 2 & 1 \\
\hline $\begin{array}{l}\text { Number confirmed with documentation } \\
\text { (MOU/Minutes) }\end{array}$ & 2 & 0 & 0 \\
\hline No Committee & 2 & 2 & 2 \\
\hline
\end{tabular}

In two of the Model woredas, the findings were less promising. In one woreda, despite the fact that respondents have all been in their positions more than five years, they were not very aware of the NNP and their sectors' roles in implementation. None of the respondents were aware of or raised any comment about the formation of woreda nutrition technical committees, although they suggested that the creation of one would be very important to collaboration, explaining the need for steering and technical committees composed of experts to focus, guide planning and budgeting, and provide leadership. Mostly, all were unaware of any existing coordination body but they highlighted the need for a lead institution to focus on nutrition and require a percentage of bureau budgets go towards nutrition programs. In regard to multisectoral coordination, one respondent replied: "In general the awareness of multisectoral coordination is a new thing for us and there is no such structure."In regard to ENGINE, the participants in 
one of these two woredas had a more negative response, indicating that they were not invited or included as sectors and that the resources only went to a small segment of the population. In the other, the feedback was more positive and many of the respondents thanked and credited ENGINE for giving them all of their training and knowledge in nutrition, in addition to other activities in the community.

In two of the non-Model woredas, participants highlighted the fact that both coordination bodies and technical committees had been established by ENGINE or Save the Children International, but that once the program ended, they were no longer functional. In one case, they mentioned high turnover as a challenge, citing that only one person previously involved in the technical committee was still present, and that the technical meeting was the first time that many of the technical focal persons had met in person. Both groups expressed the importance of having a technical committee and how it should be strengthened so that there would be clear leadership and structure for coordination. In the other two woredas, there was no awareness of a technical committee, although one group mentioned that ENGINE had encouraged sectoral collaboration, which ended with the project. They also were not very familiar with the NNP structure or design, but could articulate the problems with sectors working independently, "Within a sector to follow the nutritional activities, there is a problem of work load. Now here all sectors are available on this meeting. In previous days, there is no such kind of meeting that includes all sectors. And there is no discussion on the results of any activities. So, because of collaboration problem and program load, there is a problem of following these activities."

In the non-ENGINE woredas, one woreda during focus group discussion reported a functioning coordination body and technical committee, although this was unconfirmed by documentation. In the other woredas, one focus group discussant reported having received some support but "the coordination is not functional/strong because offices are always busy with their regular activities." The remaining groups were unaware of any nutrition committees or coordinating bodies at the woreda level.

Overall, the one word that came up in all of the FGDs was "awareness." Participants in the FGDs noted that raising awareness within the community and among sectoral heads is needed to teach healthy behaviors and ensure that nutrition and multisectoral coordination are given attention. This could guarantee that they receive nutrition training and focus attention on more than just their independent jobs and sector plan.

A series of issues related to implementation were widely presented and discussed. The topic of better coordination was a consistent theme from FGDs. The question of what was meant by better coordination led to a lively discussion in all four regions about (1) the inconsistency of how the NNP was implemented at the woreda level, (2) the need for and/or lack of integration of nutrition planning within different sectors, (3) better definitions of the exact roles and responsibilities of actors/stakeholders involved in the NNP (due to high turnover, lack of training or unfamiliarity with NNP document), (4) more emphasis on an active, multisector coordinating body, and (5) high turn-over of focal persons. Even where participants observed that nutrition coordination was getting better, it was noted that there is still enormous room for improvement. Where multisectoral coordination bodies were non-existent or non-functional, the need for 
"ownership" of the NNP and the authority for the coordinating body to carry out the plan was seen as critical for successful coordination.

While it was a common theme that functionality of the coordination bodies and technical committees ended when support ended, it was unclear that there was a single reason why this was so. High staff turnover, lack of strong leadership, and lack of oversight/accountability all seemed to be contributing factors in various degrees. On the constructive side, all participants were very positive about the potential for collaboration and its potential benefits, and their recommendations for how to accomplish better coordination were very much in line with the implementation plan of the NNP. A quote from a non-Model focus group discussion reinforced this message:

First there must be a recognized body/somebody should own it (the NNP) - who is responsible for the activities; we mentioned earlier structure, manpower and budget. However, it is important to assign a responsible body to integrate the sectors; assign each activity, plan ...currently we do not know who takes responsibility to undertake these activities.

A summary comment from another non-ENGINE focus group discussion reinforces this sentiment:

The main thing is there should be a responsible body for this issue... we have to have a responsible body that is formed as a committee.

\section{Nutrition And Health Related Problems}

In both the KI individual interviews and focus group discussions, there were a series of initial questions about the nature of the nutrition problems in the locality and existing constraints to the provision of nutrition services. Unlike the earlier governance study [7] where specific nutrition issues were cited malnutrition, stunting, micronutrient deficiencies - in this series of interviews, there was noticeable attention placed by the respondents on awareness, or rather, a lack of awareness or knowledge in the community about healthy behaviors. The issue of awareness was prevalent in responses from the KI individual interviews as well as collective discussions from the focus groups.

There is no wide spread awareness...So lack of awareness (is a major problem).

Health Office, KII

This quote is reinforced by comments from the focus groups:

The biggest problem in our society is awareness problem.......the problem of nutrition has already been mentioned but in general the problem is lack of awareness.

Focus Group, Non-Model 
The nutrition situation in this woreda is not improved. The problem is....there is lack of awareness problem in communities.

Focus Group Discussion, Non-Model Woreda

These quotes from the same focus group discussion highlight the fact that the level of awareness is perceived as a key challenge to addressing nutrition problems and the success of the NNP. This theme of better nutrition awareness in the community was the most consistent comment noted from the focus group discussions, $\mathrm{Kl}$ individual interviews, and regional observations.

A hint at an explanation of causality of health problems emerged when the respondents were asked what programs they were aware of that focused on nutrition; ENGINE was identified as the program with the highest level of awareness. Not surprisingly, $52.2 \%$ of MW and $62.5 \%$ of NMW flagged the ENGINE program, with zero percent of the NEW indicating an awareness of ENGINE. Other programs working on nutrition in the woredas included World Vision and UNICEF.

Another question from the key informant interviews asked respondents about whether or not families in the community could express their nutrition related needs and what the needs were. Overwhelmingly, water was noted as the number one identified need, with $39.1 \%, 37.5 \%$ and $58.3 \%$ in MW, NMW and NEW, respectively.

The three categories of woredas, on average, reported that $70.4 \%$ had groups in their community that were hard to reach in their nutrition work. When this issue was probed further, the main reason given was bad roads/transportation/topography; this constraint was noted by $45.8-69.6 \%$ of the respondents. Lack of budget was the second reason given for households that were hard to reach, but the percentage of respondents suggesting this reason was significantly less, ranging from $34.8-41.7 \%$.

\section{Nutrition Focal Persons by Sector}

Related to the presence of an NNP Committee, respondents were asked about the presence of a focal point in their office (Table 3). In the Model woredas, out of the 23 sector heads interviewed, 13 reported a nutrition focal person in their sector, with $100 \%$ of health sectors and $83 \%$ of agriculture sectors reporting a nutrition focal person. The Woreda Administration and Education sectors had the lowest number of woredas with a nutrition focal person (25\%), followed by finance (33\%). 
Table 3

Nutrition Focal Person by Sample Group and Sector

\begin{tabular}{|lllll|}
\hline $\begin{array}{l}\text { Sectors reporting a focal person for } \\
\text { nutrition in their office }\end{array}$ & $\begin{array}{l}\text { Model } \\
\text { Woredas } \\
\mathbf{n = 4}\end{array}$ & $\begin{array}{l}\text { Non-Model } \\
\text { Woredas }\end{array}$ & $\begin{array}{l}\text { Non-ENGINE } \\
\text { Woredas }\end{array}$ & $\begin{array}{l}\text { Total } \\
\text { woredas }\end{array}$ \\
\hline Woreda Administrator & 1 & $\mathbf{n = 4}$ & $\begin{array}{l}\mathbf{n = 1 2} \\
(\%)\end{array}$ \\
\hline Woreda Health Office & 4 & 4 & 0 & $3(25)$ \\
\hline Woreda Water and Energy Office & 3 & 3 & 4 & $12(100)$ \\
\hline Woreda Education Office & 0 & 2 & 3 & $9(75)$ \\
\hline Woreda Agriculture Office & 4 & 3 & 3 & $3(25)$ \\
\hline Woreda Finance Office & 1 & 2 & 1 & $10(83)$ \\
\hline Total Nutrition Focal Persons & 13 & 16 & 12 & $4(33)$ \\
\hline
\end{tabular}

As the administration office is responsible for leading the coordinating body, it is surprising that there are fewer nutrition focal persons in that office. Some of the reasons given by the sectors for not having nutrition focal persons include turnover, as explained by the following quotes by an administrator: "There is no representative and focal person in our office and there is not a structure at woreda administration office to have nutrition focal person even though, the administration is expected to play a key role for the sector's better implementation in the issue of nutrition. But the good thing is that there is a focal person in every one of the sector offices." And from an agriculture head, "Currently no. We had one, but she transferred to other area.. we did not appoint a focal a person at this time." One finance sector lead said the following: "There is no person assigned for nutrition. But I heard the issues of multi-sectorial once a time. I remember our office was asked to assign one person and I hope one person assigned. But I don't know exactly whether it is for nutrition or another issue. Even though that was asked there is no active person working on such issues from our office."

\section{Training in Nutrition}

Respondents from the KIls with sector leads were also asked about whether or not they had ever received any training on nutrition. In the non-ENGINE woredas, all the woreda administrators reported receiving nutrition training, while the same was true for only half the respondents in Model and non-Model woredas. Overall, more respondents from non-ENGINE woredas reported higher involvement in nutrition trainings (15 persons) compared to Model and non-Model (12 and 11 persons respectively). 
Table 4

Nutrition Training Received by Sample Group and Sector

\begin{tabular}{|lllllll|}
\hline Sectors & \multicolumn{2}{c}{ Model } & \multicolumn{2}{c}{ Non-Model } & \multicolumn{2}{c|}{ Non-ENGINE } \\
\cline { 2 - 7 } & Yes & No & Yes & No & Yes & No \\
\hline Woreda Administrator & 2 & 1 & 2 & 2 & 4 & 0 \\
\hline Woreda Health Office Head & 2 & 2 & 1 & 3 & 4 & 0 \\
\hline Woreda Water and Energy Office Head & 2 & 2 & 1 & 2 & 1 & 2 \\
\hline Woreda Education Office Head & 1 & 2 & 2 & 2 & 2 & 1 \\
\hline Woreda Agriculture Office Head & 2 & 2 & 4 & 0 & 1 & 3 \\
\hline Woreda Finance Office Head & 3 & 1 & 1 & 3 & 1 & 3 \\
\hline Woreda Women \& Child Affairs * & 0 & 1 & 0 & 1 & 2 & 0 \\
\hline Totals & 12 & 11 & 11 & 13 & 15 & 9 \\
\hline *Chair of Women and Child Affairs was interviewed if another sector head was unavailable. \\
\hline
\end{tabular}

\section{Staff Turnover}

One issue that was mentioned in some of the focus group discussions as a challenge to coordination was staff turnover. Regardless of the reasons for the turnover, this demonstrates that while key persons were sensitized and oriented at one time, once they leave, the information is not being passed along to their successor, so there is a lack of continuity. Respondents to KIls were asked how long they had been in their current positions and this number was averaged by number of months across sectors. On average, non-Model woreda respondents had been in their positions for a little over two years, while Model woredas had the lowest average time of just under one year. The longest average was for finance heads, especially in Model woredas with an average of 60 months in office, and the shortest average was for the Water and Energy Office. Some limitations to this data can be attributed to missing information from some of the sector heads. 
Table 5

Time Spent in Current Position by Sample Group and Sector

\begin{tabular}{|llll|}
\hline Sectors & \multicolumn{3}{l}{ Average Months in Current Position } \\
\cline { 2 - 4 } & Model & Non-Model & Non-ENGINE \\
\hline Woreda Administrator & 24.0 & 32.3 & 23.0 \\
\hline Woreda Health Office Head & 22.7 & 22.8 & 31.5 \\
\hline Woreda Water and Energy Office Head & 8.0 & 18.0 & 20.7 \\
\hline Woreda Education Office Head & 8.7 & 24.8 & 24.0 \\
\hline Woreda Agriculture Office Head & 20.7 & 31.8 & 15.8 \\
\hline Woreda Finance Office Head & 59.3 & 43.5 & 29.3 \\
\hline Total & 23.9 & $\mathbf{2 8 . 8}$ & 24.0 \\
\hline
\end{tabular}

\section{Budget for Nutrition Activities}

Regarding budgeting at the woreda level, the woreda finance office is responsible for preparing the government budget, making disbursements in accordance with the approved budget, and evaluating budget performance. This person is also responsible for mobilizing resources available for nutrition and ensuring that public resources allocated for nutrition are properly utilized. The NNP documentation points out that creation of sustainable financing and budget allocation might be potential ways of measuring the commitment and level of implementation of the National Nutrition Program within specific sectors and serve as a means of measuring the level of effort each sector puts forward for nutrition programming. One of the challenges identified during the implementation of NNP I was that some implementing sectors did not sensitize their strategic plan with nutrition initiatives or allocate a budget for nutrition activities.

It has been identified, however, that for sustainable nutrition financing, issues that may arise during the implementation of NNP II include inadequate budget allocation, resource shortages, weak financial resource mobilization, and low financial/budget utilization (due to a budget gap of $38 \%$ from the overall national budget intended or required for implementing the NNP over the next five years).

In the present study, when asked about a woreda budget for nutrition specific and nutrition sensitive activities, most of the respondents indicated an overall budget shortage that hindered successfully addressing the challenges in their woredas and lack of a specific budget for nutrition activities (Table 6). When asked about the challenges to multisectoral coordination, budget was also an issue, specifically, that there was a lack of budget for implementing joint sectoral activities. Some respondents who were less familiar with the NNP wondered why there was not a specific budget for the NNP as there is for the Agricultural Growth Project (AGP). This reflects a limited understanding of the NNP and its goal to 
develop sector plans that mainstream nutrition. Instead, there is an expectation to see a separate nutrition program with a separate budget.

Table 6

Woreda Level Budget for Nutrition by Woreda Groups

\begin{tabular}{|lllll|}
\hline $\begin{array}{l}\text { Is there a woreda/office budget for the nutrition } \\
\text { and nutrition sensitive activities? }\end{array}$ & $\begin{array}{l}\text { Model } \\
\text { Woredas } \\
\mathbf{N = 2 3}\end{array}$ & $\begin{array}{l}\text { Non-Model } \\
\text { Woredas } \\
\mathbf{N = 2 4}\end{array}$ & $\begin{array}{l}\text { Non-ENGINE } \\
\text { Woredas } \\
\mathbf{N}=\mathbf{2 4}\end{array}$ & $\begin{array}{l}\text { Totals } \\
\mathbf{N}=\mathbf{7 2}\end{array}$ \\
\hline Yes, there is a nutrition budget & $8.7 \%(2)$ & $4.2 \%(1)$ & $0.0 \%(0)$ & $\begin{array}{l}4.2 \% \\
(3)\end{array}$ \\
\hline No nutrition specific budget & & & & $32.4 \%$ \\
\hline No, but included in some sector budgets & $\begin{array}{l}52.2 \% \\
(12)\end{array}$ & $25.0 \%(6)$ & $20.8 \%(5)$ & $(23)$ \\
\hline $\begin{array}{l}\text { External funding for nutrition from } \\
\text { partners/donors/NGO's }\end{array}$ & $\begin{array}{l}13.0 \% \\
(3)\end{array}$ & $12.5 \%(3)$ & $16.7 \%(4)$ & $\begin{array}{l}14.1 \% \\
(10)\end{array}$ \\
\hline
\end{tabular}

One of the unique aspects of this study is the inclusion of woreda finance sector leadership. In the Model woredas, overall, there was a lack of familiarity with the NNP and the intended implementation. Two finance sector leads from the four Model woredas were aware of the NNP and the multisectoral coordination and technical committees, although their involvement was unclear and lacked a distinct role and responsibility in their term of reference. Both respondents had been in their position for more than four years. In the non-Model woredas, only one finance sector leader was aware of the NNP, and none of them were aware of any multisectoral coordination bodies or technical committees in their woredas. All had been in their position for more than a year. In the non-ENGINE woredas, none of the finance heads had much knowledge or awareness of the NNP or any NNP activities in their woredas. Only one had any training in nutrition, and all but one had been in office for about three years.

Only $4.2 \%$ of all respondents reported that there was a nutrition budget in their woreda; this percentage was slightly higher in Model woredas (8.7\%) than the other groups, however across all three categories of woredas, the percent indicating that there was a specific nutrition budget was low, ranging from zero to $8.7 \%$. Some reported that while there was no funding specifically for nutrition, funding was used from different sector budgets to cover some nutrition activities (14.1\%) or there was some external funding for nutrition from implementing partners (32.4\%). None of the KII respondents felt that the amount of budget for nutrition was sufficient and highlighted this as one of the woreda's key challenges in addressing nutrition needs in their community.

In the cases of those woredas which did not allocate a budget for nutrition, some mentioned that development or implementing partners allotted funds to cascade nutrition specific and sensitive activities within the district action plan. Others mentioned that there was no known budget as planned from the woreda finance office and noted an absence of budget codes for nutrition, as it is commonly lumped in 
with the Maternal and Child Health $(\mathrm{MCH})$ department budget. Other heads thought that other sectors (mainly the health sector) had the budget or that it was the responsibility of the health sector. This is highlighted in the quotes below:

"The office doesn't have a budget for it but there is a budget already allocated by Save the Children International, Disaster Risk Management and Agriculture Growth Program, plus UNICEF is supporting these activities." Woreda administrator in mon-Model woreda

"The first concept of allocating budget for this sector is based on maternal and child health services, TB and HIV program are the first agenda. However, there is no specific budget code for nutrition and other services." Woreda Health Office Head, non-ENGINE

"There is no budget specific for nutrition and nutrition sensitive activities. We have a budget for all administrative expenses." Woreda Health Office Head, Model

"We have no budget allocated for this purpose. But, we have budget as a health office in general. These budgets are used for monitoring, evaluation and capacity building. We have no budgets by codes for nutrition sensitive activities specifically. The available budget at office level by itself is not sufficient but we are dividing the available budget for twelve months and use it accordingly." Woreda Health Office, Model

In addition to budgetary support, other types of support were provided from NGO projects. The most common types of support included capacity building (training) and logistical support (allowances and materials).

\section{National Nutrition Program Challenges}

Overall, while there were various levels of knowledge about the NNP and the existence and functionality of multisectoral structures, the most common theme seemed to be a problem of lack of ownership for the NNP implementation at the woreda level. While the Woreda Administrators serve as chairs of the multisectoral coordination bodies, there seems to be a lack of strong leadership and responsibility for ensuring functionality. Respondents seem to recognize the need for multisectoral coordination and a need for all the sectors to understand their responsibilities - not just to focus on their own sector activities. There also seemed to be a lack of oversight or accountability, as some of the respondents pointed out that the committees became dysfunctional when ENGINE ended because there was no one to motivate the activities. High turnover, lack of knowledge, lack of accountability, competing priorities, and lack of ownership seem to remain the biggest challenges faced at the woreda level across the woreda groups.

Although Model woredas appear to report slightly more challenges (Table 7), this appears to be more a function of a greater awareness and exposure to what is needed in order to successfully implement the NNP. While non-ENGINE respondents mostly mentioned budget, Model woreda respondents had greater insight into the importance of strong coordination and leadership, as well as training on nutrition and the 
NNP. It is also likely that since Model woredas are more likely to have received training at one time, they are also more likely to identify its need. This could reflect the positive effects of ENGINE in strengthening the multisector emphasis of NNP and the need to continue support in these areas.

Table 7

Challenges in NNP Implementation at Woreda Level by Sample Group

\begin{tabular}{|c|c|c|c|c|}
\hline $\begin{array}{l}\text { What have been the main challenges in } \\
\text { implementing the NNP at the woreda and kebele } \\
\text { levels? }\end{array}$ & $\begin{array}{l}\text { Model } \\
\text { Woredas } \\
\mathrm{N}=\mathbf{2 3}\end{array}$ & $\begin{array}{l}\text { Non- } \\
\text { Model } \\
\text { Woredas } \\
\mathrm{N}=\mathbf{2 4}\end{array}$ & $\begin{array}{l}\text { Non- } \\
\text { ENGINE } \\
\text { Woredas } \\
\text { N= } 24\end{array}$ & $\begin{array}{l}\text { Totals } \\
\mathrm{N}=71\end{array}$ \\
\hline Insufficient nutrition programming & $4.3 \%(1)$ & $4.2 \%(1)$ & $12.5 \%(3)$ & $\begin{array}{l}7.0 \% \\
(5)\end{array}$ \\
\hline Lack of budget/resources & $8.7 \%(2)$ & $4.2 \%(1)$ & $0.0 \%(0)$ & $\begin{array}{l}4.2 \% \\
(3)\end{array}$ \\
\hline Lack of collaboration/coordination & $0.0 \%(0)$ & $4.2 \%(1)$ & $0.0 \%(0)$ & $\begin{array}{l}1.4 \% \\
(1)\end{array}$ \\
\hline Lack of human resources/high turnover & $4.3 \%(1)$ & $0.0 \%(0)$ & $4.2 \%(1)$ & $\begin{array}{l}2.8 \% \\
(2)\end{array}$ \\
\hline Lack of rain/drought & $0.0 \%(0)$ & $8.3 \%(2)$ & $8.3 \%(2)$ & $\begin{array}{l}5.6 \% \\
(4)\end{array}$ \\
\hline $\begin{array}{l}\text { Lack of strong leadership/political } \\
\text { commitment/attention }\end{array}$ & $4.3 \%(1)$ & $4.2 \%(1)$ & $0.0 \%(0)$ & $\begin{array}{l}2.8 \% \\
(2)\end{array}$ \\
\hline Large number of committees & $\begin{array}{l}13.0 \% \\
(3)\end{array}$ & $0.0 \%(0)$ & $12.5 \%(3)$ & $\begin{array}{l}8.5 \% \\
(6)\end{array}$ \\
\hline Limited capacity/lack of training & $8.7 \%(2)$ & $4.2 \%(1)$ & $0.0 \%(0)$ & $\begin{array}{l}4.2 \% \\
(3)\end{array}$ \\
\hline Low awareness of nutrition in other sectors & $4.3 \%(1)$ & $0.0 \%(0)$ & $0.0 \%(0)$ & $\begin{array}{l}1.4 \% \\
(1)\end{array}$ \\
\hline $\begin{array}{l}\text { Low level of awareness of the community on } \\
\text { nutrition related issues }\end{array}$ & $4.3 \%(1)$ & $4.2 \%(1)$ & $12.5 \%(3)$ & $\begin{array}{l}7.0 \% \\
(5)\end{array}$ \\
\hline Transportation/logistics challenges & $8.7 \%(2)$ & $4.2 \%(1)$ & $0.0 \%(0)$ & $\begin{array}{l}4.2 \% \\
(3)\end{array}$ \\
\hline
\end{tabular}

Frustration with the lack of more progress on collaboration is captured by the following quotes from Klls:

Before working on nutrition activities all sectors in our woreda should first get enough awareness about nutrition and how to collaborate with other sectors.

The main challenge is the weak collaboration of sectors.

Most of the time sector offices are worried on their own action plan there is no joint work among sector offices. The challenges are lack of cooperation and lack of budget and logistics. 


\section{Ways to Improve Collaboration}

When asked about ways in which there could be better collaboration between sectors in their woreda, the main responses included defining the roles and responsibilities of the sectors, as well as making them responsible for nutrition activities (16.9\%), appointing a responsible coordinator or nutrition focal person to lead, organize and evaluate collaboration (28.2\%) (Table 8), and improving the coordination, collaboration and shared sector planning (26.8\%). Respondents in the non-ENGINE woredas also mentioned additional budget (20.8\%), more attention and leadership from the government (4.2\%), and the need for an external budget (8.3\%). This question was asked of all respondents regardless of awareness of the NNP, to inquire more generally how collaboration between the sectors could be supported.

Table 8

Factors for Improved Collaboration

\begin{tabular}{|c|c|c|c|c|}
\hline $\begin{array}{l}\text { Are there any ways in which sectors could } \\
\text { collaborate more effectively together in this } \\
\text { woreda? }\end{array}$ & $\begin{array}{l}\text { Model } \\
\text { Woredas } \\
\mathrm{N}=\mathbf{2 3}\end{array}$ & $\begin{array}{l}\text { Non- } \\
\text { Model } \\
\text { Woredas } \\
\mathrm{N}=\mathbf{2 4}\end{array}$ & $\begin{array}{l}\text { Non- } \\
\text { ENGINE } \\
\text { Woredas } \\
\mathrm{N}=\mathbf{2 4}\end{array}$ & $\begin{array}{l}\text { Totals } \\
\mathrm{N}=71\end{array}$ \\
\hline Additional budget & $4.3 \%(1)$ & $4.2 \%(1)$ & $20.8 \%(5)$ & $\begin{array}{l}9.9 \% \\
(7)\end{array}$ \\
\hline Capacity building & $\begin{array}{l}13.0 \% \\
(3)\end{array}$ & $0.0 \%(0)$ & $8.3 \%(2)$ & $\begin{array}{l}7.0 \% \\
(5)\end{array}$ \\
\hline Defining roles and responsibilities of sectors & $\begin{array}{l}17.4 \% \\
(4)\end{array}$ & $16.7 \%(4)$ & $16.7 \%(4)$ & $\begin{array}{l}16.9 \% \\
(12)\end{array}$ \\
\hline $\begin{array}{l}\text { Appointing a nutrition focal person(s) to lead } \\
\text { coordination (better leadership) }\end{array}$ & $\begin{array}{l}34.8 \% \\
(8)\end{array}$ & $12.5 \%(3)$ & $37.5 \%(9)$ & $\begin{array}{l}28.2 \% \\
(20)\end{array}$ \\
\hline External support & $0.0 \%(0)$ & $8.3 \%(2)$ & $4.2 \%(1)$ & $\begin{array}{l}4.2 \% \\
(3)\end{array}$ \\
\hline Improved kebele-level coordination & $8.7 \%(2)$ & $0.0 \%(0)$ & $0.0 \%(0)$ & $\begin{array}{l}2.8 \% \\
(2)\end{array}$ \\
\hline Improved collaboration \& shared planning & $\begin{array}{l}13.0 \% \\
(3)\end{array}$ & $\begin{array}{l}41.7 \% \\
(10)\end{array}$ & $25.0 \%(6)$ & $\begin{array}{l}26.8 \% \\
(19)\end{array}$ \\
\hline More attention/importance on nutrition & $4.3 \%(1)$ & $12.5 \%(3)$ & $8.3 \%(2)$ & $\begin{array}{l}8.5 \% \\
\text { (6) }\end{array}$ \\
\hline More attention/leadership from gov't & $0.0 \%(0)$ & $0.0 \%(0)$ & $4.2 \%(1)$ & $\begin{array}{l}1.4 \% \\
(1)\end{array}$ \\
\hline
\end{tabular}

It is clear that many of the recommendations from respondents closely matched the intended implementation and structure of the NNP. Many respondents pointed to the successes of other technical committees, such as part of the AGP or One WASH programs. So, there is an understanding of the important role that these committees can play if they have strong leadership, consistency and follow-up. 
A lot of the recommendations from participants also focused on leadership and accountability - there was not a sense that it was clear who was responsible for leading the multisectoral coordination or coordination around nutrition, and that the sectors were not fully aware of their roles and responsibilities regarding integration of nutrition into their annual planning. The sectors and sector heads are often very busy with other competing priorities, so collaboration needs to be seen as a priority and not an additional, add-on activity to other tasks. There was also a sense that no one was holding the woreda accountable to the NNP, as highlighted in some of the previous quotes about activities fading out after ENGINE was no longer there to initiate activities. In the focus group discussion, some of the members of functioning technical committees said that due to the competing responsibilities of the sector heads, it would help if the technical committee could be given more authority or responsibility in driving coordination and implementation of joint planning. Some additional results are shown (Table 8).

\section{Discussion}

There has been significant progress between the ENGINE study on governance [7] and implementation of the NNP and the current 2018 research. Unlike the governance research conducted under ENGINE, the Growth through Nutrition research provides a better understanding of not simply "what" the situation is but also the "why." This fine-tuned understanding has been facilitated by a combination of focus group discussions and individual informant interviews discussed in this paper. For example, it became clear that awareness of the NNP and implementation of its structure and plan involve complex issues challenged by high turnover, competing priorities, lack of leadership and understanding of roles and responsibilities. Therefore, different strategies need to be employed to create better awareness, ownership, understanding, and motivation for policy/decision making officials, technical experts, coordinating bodies, and supporting organizations.

Despite these daunting factors, progress has been made in the intervening time period. For example, awareness of the NNP itself was higher in 2018 compared with 2014/2015, with more than one-third of all study woreda respondents aware of the NNP. This awareness is even higher for the Model woredas with almost half $(47.8 \%)$ cognizant of the NNP. This higher awareness of the NNP in Model woredas is encouraging and may reflect the effects of a greater level of technical support in these woredas. Overall, however, we would hope to see a higher level of awareness from areas that received direct support. The less than expected level of awareness may be due to high turnover of sector leadership. Generally, the average number of months in the current position for woreda sector leads is lowest in Model woredas, highlighting the need for continued sensitization and better information management.

There are other indications that Model woredas have been more successful in critical aspects of the NNP. Aside from the greater awareness in Model woredas, the MWs also have a higher percentage indicating the presence of sectoral nutrition focal persons and functional coordination bodies, although challenges do still exist. 
Operational issues such as the need for more collaboration/coordination and calls for stronger leadership have been flagged as constraints to functional coordination in Model woredas more so than in non-Model and non-ENGINE woredas. In addition, Model woredas have consistently identified the need for more capacity and clearer identification of specific roles and responsibilities as essential elements for achieving progress in the NNP. Each of these concerns could reflect the fact that the Model woredas have more awareness and experience working on implementing multisectoral activities and as a result, are clearer on the critical constraints for taking this to a more advanced level of operation.

This research also reinforces a growing body of evidence looking at multisectoral coordination more globally. Initiatives such as Feed the Future (FtF) [8] and the Scaling up Nutrition (SUN) Movement [9] have stressed investment in capacity development and facilitating an enabling environment both in Ethiopia as well as other countries. The lynchpin of these efforts is the focus on increasing awareness among stakeholders at all levels and creating and sustaining commitment to multisectoral nutrition plans. For example, from 2007 to 2014, Uganda, with support from FtF, provided technical assistance under the Food and Nutrition Technical Assistance (FANTA) project [10]. Somewhat similarly, in 2013, efforts in Malawi coordinated by FANTA were launched to increase capacity to ensure an enabling environment for nutrition [11]. This technical assistance has focused on linking a set of interrelated conditions in legal, fiscal and operational parts of government. The challenge continues to be ways to increase capacity for multisector planning and implementation at all levels.

An essential objective for this research was to use the results to identify potentially high payoff changes and/or additions that can be used going forward to increase the effectiveness of multisector nutrition planning in Ethiopia and in other countries.

It needs to be emphasized that there is not a "one size fits all" approach that can be universally applied. There are context specific issues that will need to be addressed, in addition to generally applicable recommendations. With these caveats in mind, some overarching recommendations are apparent.

Awareness and communication regarding the NNP is critical at all levels. To that end, quarterly briefs focused on cutting-edge policy information geared to high level policy officials both at National and Regional Levels could help maintain the momentum for multisector plans. A model for this is in Kennedy/Coates [12], which focused specifically on evidence-based approaches to increase the dietary impact of agriculture-nutrition strategies.

These briefs could be reinforced by in-person learning events focused on a synthesis of operational issues related to implementation of the NNP and/or challenges to multisector coordination. These events would be conducted at both national, regional and woreda levels. These meetings could pull together both Ethiopian data and relevant information from other countries and international institutions.

Engagement of leaders at the highest levels is critical for maintaining visibility and awareness of the importance of the NNP II. Similar to the success in Uganda [10], Ethiopia could identify and implement 
recurring ways to engage the Parliament. This provides a forum for refreshing the awareness and successes with the NNP II and also potentially be a way of advocating for the NNP II.

There needs to be an identification of novel ways to support technical assistance and learning. For example, video modules focused on GoE leadership at the regional and woreda levels would be useful in filling information gaps. The topics of these modules would be determined by a survey of the intended audiences, especially on the NNP implementation plan and the roles of all sectors in implementation.

There is a critical need to work with woreda sector heads to encourage that more responsibility be given to woreda technical committees to plan and implement joint nutrition activities.

There is a high turnover of staff at all levels. This creates a number of challenges including lack of institutional memory. To fill these gaps, future activities by the GOE could initiate provision of frequent orientation to new staff or encourage development of an organizational culture where staff transfer all knowledge and documents to new staff joining the organization. This would include sensitization for the sector heads on the role of their sectors in the NNP.

Documentation of the status of coordinating bodies was weak in many woredas. Standardization and training in documentation of meetings, activities, and functionality is sorely needed. This could also help fill some of the existing information gaps with new staff joining the organizations. In addition, sharing of experiences among the woredas would provide a practical forum for discussing challenges and successes in implementing the NNP II.

Joint sector planning, implementation, and monitoring and evaluation are very important to ensure successful implementation of the NNP II. Results from this study are clear about the need to support woreda joint performance review meetings and provide capacity building support to appropriate woreda technical committees to ensure the committees have the required skills and knowledge, including implementation and capacity for multisectoral planning, monitoring and evaluation, and the capacity to provide support to multisectoral coordination activities at the local level.

Innovative strategies that have been used at the national and regional levels could be employed at the woreda level. For example, the current method of using a Scorecard at the federal and regional levels has been one way to ensure accountability [13]. The use of the scorecard could facilitate the engagement and achievements in each sector in implementing the NNP II.

Since there did seem to be some positive outcomes from the Model Coordination Body approach, the GOE should continue with this system and reevaluate again after a longer period of sustained support. As part of this, the government needs to consider pathways of adequately disseminating information as the program changes, and ensure that woreda level actors are adequately informed and responsive to changes at the national level.

Government leadership above the woreda level should ensure that woreda leadership understands that the NNP is a government plan and priority. There needs to be clear government ownership of the program 
communicated at the regional and woreda levels. Woredas should not associate the multisectoral coordination committee with ENGINE or Growth through Nutrition, but as a government plan and priority. This is imperative if the longer term viability of the multisector plan is to be maintained.

\section{Conclusion}

The challenges presented in this study may seem insurmountable, but it is important to emphasize that progress has been made. The Government of Ethiopia has built its multisector plan on a strong base. Discussions by senior ministry officials about the post-2020 nutrition strategy provide an existing forum for building on strengths and continuing to ensure that the nutrition strategy and nutrition plans are relevant to the needs of Ethiopia.

\section{Abbreviations}

AGP Agricultural Growth Project

DHS Demographic and Health Surveys

ENGINE Empowering New Generations to Improve Nutrition and Economic Opportunities

EPHI Ethiopian Public Health Institute

FANTA Food and Nutrition Technical Assistance

FGD Focus group discussions

GoE Government of Ethiopia

IRB Institutional Review Board

KIlls Key Informant Interviews

MCH Maternal and Child Health

MW Model woredas

NEW Non-ENGINE woredas

NGO Non-Governmental Organization

NMW Non-Model woredas

NNP I National Nutrition Program I

NNP II National Nutrition Program II 
NNS National Nutrition Strategy

RNCB Regional Nutrition Coordinating Bodies

RNTC Regional Nutrition Technical Committees

SBCC Social and Behavior Change Communication

SCI Save the Children International

SUN Scaling up Nutrition

UNICEF United Nations Children's Fund

USAID U.S. Agency for International Development

WNTC Woreda Nutrition Technical Committees

\section{Declarations}

\section{Ethics Approval and consent to participate}

Ethics approval for this study was obtained from Tufts University. The Tufts Institutional Review Board (IRB) approved the study protocol (\#1707034) as well as the Ethiopian Public Health Institute (EPHI). Informed consent was obtained from FGD participants and individual key informants.

\section{Consent for Publication}

Not applicable

\section{Availability of Data and Materials}

The datasets used and/or analysed during the current study are available from the corresponding author on reasonable request.

\section{Competing Interests}

The authors declare that they have no competing interests.

\section{Funding}

This report was made possible through support provided by Feed the Future, the U.S. Government's Global Hunger and Food Security Initiative, through the U.S. Agency for International Development, under the terms of agreement No. AID-633-A-16-0007. The opinions expressed herein are those of the authors and do not necessarily reflect the views of the U.S. Agency for International Development. 


\section{Authors' Contributions}

EK contributed to the analysis and interpretation of study results and drafted the manuscript. MK and SB participated in the design of the study, coordination and statistical analysis. All authors participated in the revision process and read and approved the final manuscript.

\section{Acknowledgements}

Not applicable

\section{References}

1. Government of the Federal Democratic Republic of Ethiopia. National Nutrition Strategy. Addis Ababa: Federal Ministry of Health (Ethiopia); 2008.

2. Government of the Federal Democratic Republic of Ethiopia. National Nutrition Programme: 20082015. Addis Ababa: Government of Ethiopia; 2008.

3. Government of the Federal Democratic Republic of Ethiopia. National Nutrition Strategy: 2015-2020. Addis Ababa: Federal Ministry of Health (Ethiopia); 2016.

4. Government of the Federal Democratic Republic of Ethiopia. Seqota Declaration; 2015. Available from: https://www.bigwin.org/nm_pent_bigwp/wp-content/uploads/2019/10/ExtendedNote.pdf

5. Central Statistical Authority [Ethiopia] and ORC Macro. Ethiopia Demographic and Health Survey 2000. Addis Ababa, Ethiopia and Calverton, Maryland, USA: Central Statistical Authority and ORC Macro; 2001.

6. Ethiopian Public Health Institute (EPHI) [Ethiopia] and ICF. Ethiopia Mini Demographic and Health Survey 2019: Key Indicators. Rockville (MD), USA: EPHI and ICF; 2019.

7. Kennedy E, Tessema M, Hailu T, Zerfu D, Belay A, Ayana G, et al. Multisector nutrition program governance and implementation in Ethiopia: opportunities and challenges. Food Nutr Bull. 2015; 36(4):534-548.

8. Feed the Future: Improving Food Security and Nutrition Around the World. Washington DC: USAID; 2010.

9. United Nations System Standing Committee on Nutrition (UNSCN). The Scaling Up Nutrition Movement. 2011. Available from: https://www.unscn.org/en/forums/Relevant-Platforms? idnews $=1280$.

10. FANTA III: Food and Nutrition Technical Assistance - Uganda. 2015. Available from: https://www.fantaproject.org/countries/uganda.

11. FANTA Gears Up to Support Malawi's Efforts to Improve Nutrition. 2017. Available from: https://www.fantaproject.org/countries/malawi.

12. Kennedy E, Coates J. Food Systems: Pathways for Improved Diets and Nutrition. Curr Dev in Nutr. 2018; 2(9). Available from: https://doi.org/10.1093/cdn/nzy027 
13. African Leaders Malaria Alliance (ALMA). Ethiopia - Country Scorecard. 2019. Available from: http://www.alma2030.org/scorecards 